\title{
A máquina de guerra contra o Estado tóxico: captura e conjuração estatal na luta pelos direitos da população de rua
}

The war machine against the toxic state. Capture and state conjuring in a struggle for rights of homeless people

\section{Tiago Lemões}

\section{(2) OpenEdition Journals}

\section{Edição electrónica}

URL: https://journals.openedition.org/aa/3760

DOI: $10.4000 /$ aa. 3760

ISSN: 2357-738X

\section{Editora}

Programa de Pós-Graduação em Antropologia Social (UnB)

\section{Edição impressa}

Data de publição: 1 junho 2019

Paginação: 189-216

ISSN: 0102-4302

\section{Refêrencia eletrónica}

Tiago Lemões, «A máquina de guerra contra o Estado tóxico: captura e conjuração estatal na luta pelos direitos da população de rua», Anuário Antropológico [Online], v.44 n. 1 | 2019, posto online no dia 06 julho 2019, consultado o 21 setembro 2021. URL: http://journals.openedition.org/aa/3760 ; DOI: https://doi.org/10.4000/aa.3760

\section{@) $\Theta \Theta \Theta$}

Anuário Antropológico is licensed under a Creative Commons Atribuição-Uso Não-Comercial-Proibição de realização de Obras Derivadas 4.0 International. 


\title{
A máquina de guerra contra o Estado tóxico: captura e conjuração estatal na luta pelos direitos da população de rua
}

\author{
Tiago Lemões \\ Universidade Federal de Pelotas - Brasil
}

\section{Introdução}

Para muitos ativistas de direitos humanos e militantes do Movimento Nacional da População de Rua (MNPR), a madrugada do dia 19 de agosto de 2004 deixou marcas e cicatrizes profundas. Naquela noite, nos arredores da Praça da Sé, centro de São Paulo, dez pessoas que dormiam enroladas em seus cobertores foram golpeadas violentamente, resultando em seis mortes e quatro internações em estado grave. Três dias depois, um novo ataque com as mesmas características, contra cinco pessoas que dormiam em pontos não muito distantes da Praça da Sé. Mais uma vida apagou-se instantaneamente ${ }^{1}$.

Da condição de vítimas, as pessoas em situação de rua passaram a cultivar uma “comunhão entre vítimas”, reivindicando justiça, direitos e dignidade. Um ano após os acontecimentos da Praça da Sé, nascia o MNPR, espalhando-se, em pouco mais de 13 anos, por 14 estados da federação - incluindo o Rio Grande do Sul, a partir de 2013. Desde então, a formulação de tantos instrumentos governamentais de garantia de direitos e de combate às violações, coproduzidos por espaços de mobilização social, setores governamentais e narrativas de direitos humanos, passou a ser vista por integrantes do MNPR como conquista histórica, que possibilitou o reconhecimento de uma população antes "invisível” ao mundo.

Mas, a despeito de tantas "conquistas", os militantes jamais deixaram de reconhecer e denunciar a continuidade de uma conservadora e truculenta criminalização da permanência das camadas pobres e negras da população brasileira em determinados territórios urbanos. Tal cenário, que cambaleia entre a garantia de direitos e as práticas e discursos depreciativos, sempre se fez presente na cotidianidade dos integrantes do MNPR em sua base regional de Porto Alegre, capital gaúcha, onde atuei como pesquisador e apoiador da mobilização social, entre os anos de 2013 e $2017^{2}$. A pesquisa foi realizada com vistas a compreender o emaranhado de relações, debates e tensões entre apoiadores (estudantes universitários, psicólogos, educa- 
dores sociais, advogados e outros profissionais da rede socioassistencial) e militantes em situação de rua, assim como as mediações e interlocuções com diferentes agentes e instituições estatais, atentando para a potência e os limites que tais relações e interlocuções guardam na luta por direitos.

Dessa experiência, retiro o substrato das reflexões etnográficas que desenvolvo neste artigo, formado por um conjunto de mecanismos dispersos, mobilizado por militantes do MNPR para conjurar ${ }^{3}$, minar ou minimizar os efeitos perversos da presença estatal em suas lutas por direitos, reconhecimento, dignidade e, sobretudo, humanidade. Valorizo, especificamente, as interações mais cotidianas da mobilização social para identificar, nas suas justificativas e nos seus efeitos, ações que expurgam autoridades, hierarquias, autorrepresentação e poder de comando dos sujeitos (agentes estatais e/ou militantes) identificados como pertencentes ao Estado ou que com ele mantêm uma proximidade dúbia e perigosa.

Como veremos, as experiências etnográficas junto aos integrantes do MNPR em Porto Alegre deixaram cada vez mais evidente que a aproximação demasiado pacífica com o Estado deve ser estrategicamente evitada na medida em que se sabe (ou se aprende) que as instituições que "prometem" proteção são as mesmas que atuam para fins não tão "protetivos" assim - evidenciando processos de construção de um Estado tóxico (do qual se deve manter certa distância para evitar, inclusive, indesejáveis sintomas como tontura e náuseas). Do mesmo modo, incansáveis esforços individuais e coletivos são postos em marcha pelos militantes do MNPR para impedir a ascensão da figura do líder, daquele que se destaca perante o coletivo, que dialoga harmoniosamente com a institucionalidade e passa a atuar como o "sujeito ideal" das políticas públicas: recuperado, incluído, transformado, autônomo e protagonista do seu próprio destino - empenhos que se aproximam das conhecidas inferências clasterianas sobre a dissonância entre prestígio, mando e poder (CLASTRES, 2011). Por si só, esse quadro antecipa uma experiência que, em muitos aspectos, questiona e enfrenta a lógica neoliberal das promessas salvacionistas das políticas direcionadas à população em situação de rua nos últimos 10 anos.

Para potencializar as teorias nativas a respeito do Estado tóxico, retomo as contribuições de Gilles Deleuze e Félix Guattari (1996; 1997) para pensar fenômenos simultâneos de captura e escape, materializados nas forças estatais que buscam tudo interiorizar e neutralizar, mas também nos questionamentos, nas indisciplinas, nos motins, nas traições, nos deboches e em tudo que promove fuga - ainda que momentânea e situacional. A concentração estratégica destas forças de escape 
é compreendida pelos autores como máquina de guerra, que atua por oposição aos conjuntos hierarquizados de controle e centralização, criando zonas de impotência dos poderes ordenadores e acionando vetores nômades, minoritários e micropolíticos voltados à implosão de forças de fixação e sedentarização (DELEUZE \& GUATTARI, 1997). Como ficará mais claro nas próximas páginas, pensar a população em situação de rua como máquina de guerra permite explicitar e valorizar a dimensão combativa das relações travadas entre integrantes do MNPR e os agentes e instituições estatais, no intento de iluminar os modos pelos quais, a um só tempo, se acessam e se conjuram focos de autoridade e captura com pretensões totalizantes.

Antes, porém, faço um alerta: todas as experiências etnográficas apresentadas neste texto foram vivenciadas em um universo de interações masculinas, o que de imediato apresenta implicações importantes nas reflexões elaboradas. Se, por um lado, sabemos que a mobilização social pelos direitos da população de rua conta com o protagonismo feminino, o fato de que ações de contraposição estatal sejam majoritariamente conduzidas por homens, nos revela os limites da participação das mulheres, impostos pelas desigualdades de gênero no acesso aos espaços de fala e visibilidade política - o que, de certa maneira, também ocorre em relação aos militantes LGBTT's ${ }^{4}$. Essa questão torna-se ainda mais importante porque estudos recentes têm revelado a dimensão dramática de mulheres em situação de rua, para as quais o homem, no contexto das ruas, é a manifestação paradoxal de violência e proteção (Fernandes, 2019); assim como têm explicitado o modo como questões de gênero são minimizadas pelas políticas públicas e pelas lutas sociais, que acabam por homogeneizar a experiência de rua, invisibilizando suas multiplicidades (Sarmento, 2017).

Com isso, ressalto dois pontos importantes que devem ser considerados ao longo da leitura deste texto: (1) o artigo trata de um recorte de experiências etnográficas nas quais o protagonismo de homens em situação de rua é predominante - o que inevitavelmente expressa um recorte de gênero que incide sobre as reflexões e interpretações aqui realizadas; (2) justamente por isso, as inferências e conclusões analíticas não se pretendem generalizáveis sobre a pluralidade dos modos de vivenciar a situação de rua e de reivindicar direitos, sobretudo aqueles marcados por atravessamentos de gênero e sexualidade que sobrevêm de forma desigual no contexto empírico a ser explorado. Considerando estas questões, fica claro, desde agora, que pensar a população de rua como máquina de guerra é falar desde um lugar empiricamente circunscrito ao universo masculino da mobilização social -que é, pode e deve ser enriquecido e contraposto por outras perspectivas e lugares de 
fala que povoam a luta por direitos ${ }^{5}$.

\section{A temporalidade do Estado tóxico}

Antes de adentrar propriamente no contexto etnográfico, me parece oportuno tecer algumas considerações sobre a natureza diacrônica da toxidade estatal evidenciada pelos interlocutores ao longo do percurso etnográfico, o que de muitas formas fundamenta a crítica constante às aspirações humanitárias que se cristalizam nas políticas assistenciais.

Há algum tempo tenho insistido, em diálogo com um corpo heterogêneo de autores, nos múltiplos esforços empreendidos para barrar a presença de corpos marcados por indexações raciais no espaço urbano brasileiro desde o final do século XVIII (Lemões, 2017). Corpos e existências contra os quais foram levantadas barricadas para anestesiar qualquer revanche frente à perversidade do sistema escravista. Vidas que, posteriormente, no alvorecer da Primeira República, foram alvo de arquitetados mecanismos de docilização, dispositivos e estratégias pedagógicas para regenerar e recuperar corpos indesejáveis, numa fusão imaginativa entre raça, crime, ociosidade e mendicância. A isso se seguiu uma violenta transformação estética dos espaços urbanos, conduzida por deslocamentos forçados e justificada por elucubrações intelectuais que interpunham certas vidas numa encruzilhada entre ciência, burocracia estatal e práticas policiais muito específicas, voltadas aos que "manchavam" o projeto moderno-civilizacional em curso na América Latina.

Posteriormente, no marco do poder político-militar, com expressão máxima no período ditatorial brasileiro, novas categorias e modos de intervenção foram eleitas: os “desajustados” eram, também, "inimigos internos”, os quais a assistência social teve por finalidade amparar e conduzir por caminhos de recuperação. Tal situação começou a ser denunciada ou ao menos visibilizada pelo lento e gradativo surgimento de movimentos contestatórios, religiosos e filantrópicos que buscaram sobretudo remover o manto da culpabilização individual sob o qual se escondia o peso das desigualdades estruturais - o que, de alguma forma, preparou as condições de existência para o MNPR ao longo da primeira década do século XXI. Já sabemos, no entanto, que a emergência de uma retórica dos direitos, no Brasil, foi acompanhada pela exasperação de intervenções violentas, vivificadas no entrecruzamento de políticas de segurança e assistência ${ }^{6}$.

Nesse cenário, as práticas de apagamento e aniquilamento foram metamorfoseadas no seu espraiamento espaço-temporal, gritando aos nossos ouvidos que a vio- 
lência do projeto civilizacional não reside apenas num passado distante, mas mora ao lado, na frente, nos fundos. Vive dentro. Dorme conosco e nos habita - logo nós, os humanistas! Sua expressão reside na verificável confluência de práticas aparentemente antagônicas de gestão de populações e de territórios que lhes são associados. Trata-se de intervenções múltiplas que conjugam a discursividade da proteção, da defesa, da segurança, da recuperação, com práticas de remoção que, se não promovidas pelo aconselhamento de agentes bem-intencionados, são inevitavelmente consumadas pelo poder policial.

Quando insisto na continuidade e metamorfose de certas políticas e modos de gestão, me coloco em comum acordo com De Lucca (2008), para quem a retroalimentação de todo esse aparato é constituidora de um dispositivo de segurança social que busca prevenir os riscos que ameaçam a reprodução de certas vidas na cidade, fazendo com que políticas de expulsão e acolhimento sejam conjuntamente efetuadas em nome da "proteção social" e da "limpeza das ruas". É o que também se aproxima do que Loïc Wacquant (2013) vem caracterizando como dupla composição de um "Estado Centauro" em políticas de miséria urbana nos Estados Unidos, sobretudo porque suas dimensões penal e social visam à mesma "população" (apreendidas no fosso de uma estrutura socioespacial polarizada) e se utilizam das mesmas técnicas: cadastros, vigilância, classificações depreciativas e sanções graduais.

Portanto - o que já não é novidade para ninguém -, esse Estado que garante um feixe de direitos e proteções é o mesmo que perpetua ações violentas e fecha os olhos frente à possibilidade de justiça para as vítimas de variadas brutalidades. Situação que vem sendo atualizada desde pelo menos o final do período escravocrata, quando corpos negros passaram a reivindicar estatuto ontológico que lhes fora historicamente negado. Não por acaso, as pessoas que compõem o alvo privilegiado do Estado, como os militantes e apoiadores do MNPR, sabem muito bem como funciona a articulação das forças violentas e protecionistas da intervenção estatal, cujos efeitos não encontram apenas resistências ou contrapontos momentâneos, facilmente transponíveis pelo convencimento. Mais que isso, as ações coletivas e individuais, a um só tempo, constroem o Estado e o transformam em uma força a ser evitada ou deslegitimada, opondo toda uma maquinaria de guerra contra a toxidade estatal.

\section{A máquina de guerra e a fazenda de domesticação}

No Tratado de Nomadologia, Deleuze e Guattari (1996; 1997) refletem sobre a formação de poderes concentrados e totalizantes e os mecanismos coletivos desti- 
nados à sua inibição ou extermínio. O Estado, para os autores, é um fenômeno de intraconsistência que opera por estratificação, formando um conjunto vertical e hierarquizado que atravessa linhas horizontais, cortando suas relações e criando, assim, a exterioridade a ser abarcada e com a qual as relações serão cada vez mais controladas, retardadas ou inibidas. Nesse movimento, o Estado só pode reunir aquilo que isola por subordinação. Ao fazer isso, essa espécie de aparelho de captura sobrecodifica, territorializa, combate ou integra as potências nômades e seus fluxos. Sua soberania reina somente sobre aquilo que interioriza, fazendo da exterioridade uma ameaça a ser aniquilada ou apropriada localmente, assentada num espaço estriado, domesticado, domado. Sua principal função: sedentarizar a força, regrar o movimento, criar organismos, triunfar sobre uma "vagabundagem de bando" e sobre um "nomadismo de corpo".

Mas como fenômeno indissociável desse processo, a indisciplina, o questionamento da hierarquia, a constante ameaça de abandono e traição conformam as forças que contrariam e neutralizam a captura estatal. Lá onde há qualquer motim, bando, fuga ou revide inesperado, uma máquina de guerra é formada, criando uma zona de impotência onde poderes ordenadores podem até converter fluxos, mas jamais controlá-los e determiná-los. Essa máquina tem por inimigo o fenômeno estatal e assume objetivos de aniquilação, conjuração e escape, operando mutações minoritárias, populares, revolucionárias (Deleuze \& Guattari, 1997).

No entanto, aqueles autores insistem no embaralhamento dos modelos arborescentes e rizomáticos. A árvore enraíza-se, fixando-se em um ponto centralizado ao qual subordina toda a sua estrutura então sedentarizada, assegurando uma segmentaridade dura, concêntrica e molar. Rizoma, por sua vez, é rompimento; é um lado que se liberta e que pertence a um espaço liso por onde percorre sua multiplicidade nômade em constante devir e transformação. O Uno e o múltiplo aqui se despregam para narrar a oposição complementar entre a captura (o Estado) e a fuga (a potência nômade); entre a sobrecodificação dura e a inventividade fugitiva - processos imanentes um ao outro (Deleuze \& Guattari, 1997: 221).

É por meio dessa imanência que tanto a potência nômade torna-se máquina de guerra quanto o Estado cria uma imagem legítima e indivisa de si mesmo. É precisamente o que James Scott (2013) entende como celebração do Estado através da legibilidade, da recuperabilidade e da docilidade lançadas sobre populações nômades - especificamente aquelas situadas em um vasto território do sudeste asiático, onde a "arte de não ser governado" é cultivada mediante mecanismos complexos de dis- 
persão, mobilidade, fuga e organização social segmentarizada. Contra elas, há todo um léxico estatal extremamente produtivo: são desprotegidas, estão nas "bordas civilizacionais", ameaçam a coletividade, são atrasadas e grotescas como diamantes brutos (Scott, 2013).

Quando o Estado, então, se apropria da máquina de guerra, ele aproxima educação, formação e aprendizado aos supostamente destituídos (Deleuze \& Guattari, 1997). Nesse aspecto, é exemplar o estudo de Piero Leirner (2012) sobre os discursos do Exército brasileiro, nos quais a Amazônia é representada nos termos de um "inferno verde" e de um "espaço morto" a ser domesticado. Mas, no rastro de Deleuze e Guattari, o autor constrói argumentos que buscam corroer qualquer completude analítica sobre as artimanhas do Estado, compreendido como um espaço com fronteiras abertas, uma fazenda de domesticação onde se busca, sobretudo “controlar essa força conjurada de um devir selvagem” (Leirner, 2012:39). Mais do que capturar pela força, na fazenda de domesticação o convencimento supõe a ameaça constante do colapso, dos movimentos de fuga e é isso que, para o autor, guarda um esforço constante de unificação nunca eficaz, sempre diluído em fronteiras abertas, quase imperceptíveis e impossíveis de localizar. Como não há cercados, todos estão sempre fugindo e, ao mesmo tempo, persuadidos a manterem-se próximos.

Fuga e convencimento, desejo e repulsa. Pensar a população em situação de rua como máquina de guerra é indicar a complexidade das relações ambíguas travadas com os agentes e as instituições estatais, mas sobretudo dos fluxos engendrados para, a um só tempo, acessar e conjurar a potência estatal. Se forças de captura regram movimentos, localizam corpos e coletivos, tentam cristalizar poderes e centralizar saberes; produzem discursos civilizacionais, proliferam práticas salvacionistas, incitam "superações", "recuperações” e engajamentos múltiplos, nada disso teria sentido sem movimentos outros: aqueles que se voltam contra os insistentes focos de concentração de força, de autoridade, de superioridade, num impulso de impedir o "chefe de ser chefe" (Clastres, 2011). E isso parece ocorrer de muitas formas - todas elas manejadas no mesmo instante em que a sempre incompleta captura mostra a sua força.

Para analisar especificamente os modos de atuação dessa máquina de guerra no coração e na exterioridade da fazenda de domesticação, convém lançar alguns questionamentos retóricos. É possível ficar no interior da fazenda e fingir estar convencido de que ali é o melhor lugar, ludibriando, revidando e afrontando? É possível que, mesmo no enredo de linhas de captura sedentarizantes, a potência nômade 
continue a operar nos interstícios do aparelho estatal? É presumível que se criem benfeitorias distintas, momentâneas, rizomáticas, dentro da fazenda de domesticação?

Por fim, é possível manter a certeza de que as forças nômades que se sedentarizam são, de fato, passivamente capturadas ou nada mais fazem do que se enraizarem estrategicamente para questionar a autoridade dos funcionários da fazenda? Vejamos o que os militantes em situação de rua têm a nos dizer sobre isso.

\section{A toxicidade das palavras}

Com pouco mais de 250 mil habitantes, o município de São João ${ }^{7}$ integra a região metropolitana de Porto Alegre, distando cerca de $40 \mathrm{~km}$ da capital. Foi para lá que nos dirigimos, eu e Diego, militante em situação de rua, em maio de 2016, atendendo ao chamado de um vereador que recebera, cerca de um mês antes, um ofício, assinado por integrantes do MNPR-RS, solicitando uma audiência pública para debater o cenário da assistência social na cidade.

Em contato com funcionários da rede de acolhimento daquele município, o MNPR-RS recebera uma série de reclamações informais sobre a precariedade dos serviços disponibilizados às pessoas “em situação de rua” de São João. À época presidindo a Comissão de Direitos Humanos e Defesa do Consumidor, o vereador ficou intrigado com a solicitação - cujo documento salientava a importância da presença dos responsáveis pelas áreas de cidadania, saúde, habitação, segurança e direitos humanos - e achou melhor conversar com os solicitantes para obter maiores esclarecimentos. Foi quando Diego me pediu que o acompanhasse nesse primeiro encontro com o vereador de São João.

Na primeira hora da tarde, nos encontramos em um terminal rodoviário, em meio à agitação de tantas pessoas circulando, correndo ou aguardando suas conduções. Durante a viagem, Diego atendeu o telefonema de uma secretária do vereador e recebeu a informação de que só poderíamos ser atendidos após às 17 horas, pois uma agenda com o prefeito atrasaria os compromissos da Câmara naquela tarde. Desconfiado de uma possível estratégia para que desistíssemos da reunião, Diego deixou claro que não haveria nenhum problema e que esperaríamos o tempo que fosse necessário.

Mesmo assim, teríamos que tomar muito cuidado com nossos posicionamentos. Para Diego, era fundamental que não demonstrássemos nenhum sinal de enfrentamento ou discordância. Em um ônibus lotado e faltando percorrer ainda a metade do caminho até o nosso destino, questionei aquela informação, que parecia chegar 
tardiamente até mim. Diego esclareceu que se tratava de uma estratégia: o tom da conversa deveria ser amigável pois, caso contrário, correríamos o risco de ter o pedido de audiência negado. Posteriormente, quando estivéssemos em diálogo público com as autoridades convidadas, poderíamos expor todos os questionamentos e denúncias necessárias. Por hora, teríamos que afirmar ao vereador que a audiência seria uma oportunidade de conhecer melhor os serviços existentes no município e firmar diálogos importantes no sentido de contribuir com a visibilidade de ações exitosas no campo socioassistencial, conduzidas na região metropolitana. Em suma, a nossa linha discursiva deveria ser, naquele momento, de composição e diálogo com o poder público.

Ao chegarmos em nosso destino, fomos identificados na portaria e recebemos um crachá de visitante. No terceiro andar, acessamos um corredor ao longo do qual estavam dispostos os gabinetes de cada vereador e onde aguardamos por mais de uma hora e meia a incerta conversa marcada para aquela tarde. Quando estávamos quase desistindo, a porta do gabinete se abriu e a secretária nos convidou a entrar. Acessamos uma pequena sala onde cumprimentamos o vereador e seu assessor. Finalmente, sentamos para conversar. Para a minha surpresa, as primeiras palavras de Diego foram: "eu acho que o Tiago pode, então, começar a explicar o que nos traz aqui”. Conhecendo Diego muito bem, eu não esperava que fosse falar muito naquela tarde, muito menos que fosse impelido, de surpresa, a iniciar a conversa. Tive que pensar rápido e, inspirado apenas pelo que havíamos confabulado no ônibus, olhei para o vereador e disse:

Olha, para lhe explicar melhor o motivo dessa audiência que estamos reivindicando, eu gostaria de contextualizar que eu e Diego somos integrantes do MNPR, que é um movimento social conduzido por pessoas em situação de rua. Em Porto Alegre, desde 2010, esse movimento vem conquistando uma série de melhorias nos serviços socioassistenciais a partir de um diálogo com o poder público, com a FASC e com o MP. Tomando esse diálogo como referência, nós gostaríamos de realizar uma audiência pública aqui em São João por acreditarmos que podemos não só contribuir com os serviços já existentes aqui, mas também aprender com vocês a partir de experiências locais do município. Não sei se o Diego quer acrescentar alguma coisa... (Diário de campo, 19 de maio de 2016).

Diego reiterou a minha fala e foi além: 
Eu acho que é isso mesmo, Tiago. Na verdade, a nossa posição é mesmo de compor com a gestão, tentando um diálogo que nos permita, sim, aprender com vocês. Muitas pessoas em situação de rua circulam pela região metropolitana de Porto Alegre e já chegou até nós, por repetidas vezes, a informação de que o albergue municipal de São João atende as pessoas com dignidade, como deve ser feito. A nossa visão, por isso, é justamente de diálogo. Sabemos que muitos movimentos sociais têm uma postura de enfrentamento, mas nós entendemos que estamos todos do mesmo lado: gestor, trabalhador e usuário e que só assim conseguiremos avançar nas políticas públicas (Idem).

O vereador, que ouvia atentamente as nossas explicações, apresentou uma primeira resistência ao pedido de audiência, explicitando que se quiséssemos nos aproximar das práticas exitosas da assistência social, o mais indicado seria dialogar diretamente com a secretaria responsável pelos serviços direcionados à população em situação de rua. Em suas palavras...

Aqui em São João sabemos que a metade dos moradores de rua está de passagem e não fica aqui por muito tempo. Geralmente eles acessam os serviços por dois ou três dias e são encaminhados. Claro, temos também os que não querem atendimento nenhum e permanecem nas ruas. Para estes, temos a atuação das igrejas que doam sopas, roupas e ajudam da maneira que podem. Então a nossa realidade aqui é bem flutuante nesse sentido, mas o que eu não entendi ainda - e quero perguntar a vocês - é por que, ao invés de fazer uma audiência pública, vocês não se concentram em conversar diretamente com a secretaria responsável pelos serviços de assistência? Eu pergunto isso porque conversar diretamente com os serviços pode, na minha opinião, acelerar o processo de diálogo que vocês querem estabelecer" (Idem).

Eu não tinha resposta pronta para a questão. Olhei para Diego como quem pede ajuda. Sem titubear, ele já tinha uma réplica na ponta da língua:

Nós estamos trabalhando com a ideia da audiência pública porque é isso que tem dado muito certo na região metropolitana de Porto Alegre. Em Caxias do Sul, por exemplo, a última audiência foi bem produtiva porque pudemos ouvir diferentes vozes e opiniões a respeito dos serviços e isso ajuda muito em qualquer processo de melhoria. Além disso, pelas nossas experiências, uma conversa direta com os técnicos sempre acarreta certo receio e uma posição de defesa, como se estivéssemos avaliando o trabalho deles, mas a ideia não é essa (Idem). 
A composição de nossas falas, nada ensaiadas e incrivelmente bem articuladas, não deixou dúvidas sobre nossas boas intenções: o vereador mostrou-se satisfeito, cumprimentou-nos em tom de despedida e afirmou que em breve entraria em contato com Diego para combinar a melhor data para a audiência pública. Conversamos rapidamente com o assessor, que confirmou nosso contato e avisou que em breve acertaríamos os detalhes para a realização do evento.

Mas bastou entrar no elevador para que toda a encenação fosse por água abaixo. Assim que a porta se fechou, Diego manifestou dificuldades para respirar e teve náuseas. Preocupado, perguntei o que estava acontecendo e ele explicou que o mal-estar era consequência de tudo aquilo que acabávamos de falar ao vereador palavras e argumentos que nos posicionavam ao lado deles e não contra eles. Para Diego, o pior foi insinuar a criminalização dos movimentos sociais, ao frisar que a nossa postura era de diálogo e não de enfrentamento - ao contrário de outros coletivos. Ainda no elevador, confessei que o mais atormentador para mim fora elogiar os serviços locais voltados à população em situação de rua, quando o que sabíamos era que esses espaços tinham muitos problemas de maus-tratos, alimentação e instalações precárias, suspensões e expulsões constantes dos "usuários" - motivo pela qual o próprio vereador caracterizou a "realidade" dessa população como "flutuante": entrada e saída constante dos espaços institucionais, circulação entre os municípios da região metropolitana e mesmo a recusa em acessar os equipamentos institucionais.

O mal-estar foi amenizado quando já estávamos na rua e resolvemos caminhar cinco quarteirões até a praça central da cidade, onde pegaríamos o ônibus de volta para Porto Alegre. Digerindo tudo que tinha acontecido naquele curto espaço de tempo, nos impressionamos com a sincronização das nossas falas, o encaixe dos argumentos e a nossa capacidade de encenação sem nenhuma brecha para contrapontos. Rimos muito da situação e Diego passou a comemorar o fato de que tínhamos colocado o vereador "no bolso" muito facilmente. As mesmas palavras que intoxicavam - causando mal-estar e repulsa - tinham um gosto de vitória: a audiência pública seria marcada. Mas precisaríamos redobrar o cuidado com retaliações, pois havíamos utilizado as ferramentas e benfeitorias da fazenda para encenar uma captura totalizante, um posicionamento dialógico, harmônico e pacífico ao lado dos que são construídos e representados como inimigos do MNPR-RS, aqueles nos quais jamais se deve realmente confiar.

Vivenciada já no último mês de pesquisa, essa anedótica experiência com Diego 
me fez retomar os diários de campo, escritos anteriormente, e atentar para as notas que me passaram despercebidas, mas que guardavam caminhos que levavam a situações exemplares, versando sobre um reiterado desprezo pelo Estado, ainda que seus agentes e suas instituições fossem os principais apoiadores e interlocutores daquele movimento social. Naturalmente, a repulsa manifestava-se em todas as denúncias sobre a precariedade das instituições socioassistenciais, mas também - e principalmente - na manifestação do potencial tóxico das relações cordiais com seus representantes: o perigo em ultrapassar a linha tênue entre as estratégias que dissimulam o devir guerreiro (mas não o abandonam) e a possibilidade de se deixar convencer de que não há lugar melhor do aquele oferecido pelas autoridades e instituições estatais.

Desde o início da viagem, Diego deixou claro que nossas palavras deveriam ser ditas com cautela, no objetivo de encenar a captura, ou seja, de expor ideias que nos colocassem, estrategicamente, como "sujeitos ideais" para o diálogo estatal e para a construção conjunta e participativa das políticas públicas. O perigo tóxico exibia sua ameaça pela proximidade espacial, pela convergência de opiniões e pelas palavras elogiosas que nos colocavam contra os que defendíamos e ao lado do alvo de todas as nossas críticas, denúncias e contraposições. A máquina de guerra, ao fingir convencimento para, em seguida, revidar e afrontar, também sofreria consequências que se manifestariam no corpo de seus vetores e nas possíveis retaliações que poderiam brotar a qualquer instante pelos campos da fazenda. Era preciso tomar muito cuidado.

Longe de ser um caso isolado, a viagem com Diego desnudou o potencial reflexivo de outras experiências etnográficas que acabaram por reiterar e complexificar os modos de movimentação guerreira dos militantes do MNPR e dos mecanismos mobilizados para conjurar a lógica arborescente que insiste em enraizar-se no seio da luta pelos direitos da população em situação de rua.

\section{Espiões e reféns}

Em janeiro de 2016, ao final de uma reunião do MNPR-RS, cinco militantes conversavam sobre o recente ingresso em um grupo de facilitadores sociais, que atuaria na mediação entre os agentes de abordagem de rua da prefeitura e as pessoas em situação de rua, supervisionados pela a Fundação de Assistência Social e Cidadania, a FASC (responsável pela gestão da assistência social na cidade). Na conversa, dois desses militantes selecionados para o trabalho junto à instituição relataram que, ainda no curso de capacitação que realizaram para trabalhar como facilitadores, 
questionaram a coordenadora dos serviços de acolhimento institucional sobre a razão pela qual assembleias não estavam mais ocorrendo no Centro-Pop ${ }^{8}$, uma vez que, "por lei”, a população em situação de rua deveria participar da formulação e avaliação das políticas públicas. Contaram que, após o questionamento, a responsável pelo serviço, que teria ficado extremamente constrangida, garantiu que providências seriam tomadas para que as assembleias fossem reativadas. Antes de partir para outros rumos, os narradores desse curto diálogo afirmaram que "nós estamos lá, seja trabalhando para eles, seja como usuários do serviço, mas também estamos lá como espiões".

No mesmo dia em que a referida conversa foi registrada, ficamos em um grupo menor, mas ainda tocados pelo assunto há pouco iniciado pelos facilitadores. Outro militante entre nós partilhou sua opinião sobre uma espécie de "efeito refém" provocado pela relação com as instituições estatais. Em suas palavras...

Existem muitas formas de ficar refém deles. Por exemplo, no Centro-Pop não pode tomar banho, mas se eu vou tomar banho na casa do fulano, eu já fico refém. Se eu vou numa reunião com os vereadores ou com os candidatos a prefeito, se eu aceito isso ou aquilo, eu já me torno refém. Então tem muitas formas de estragar o movimento, de detonar a luta. Se o cara da FASC vem aqui no movimento e oferece um apartamento do Minha Casa, Minha Vida, todo mundo pega. Eu não vou mentir: até eu pego! Isso é uma forma de facilitar o acesso ao serviço, mas facilita para poder cooptar. Todos que conseguiram o Minha Casa, Minha Vida saíram do MNPR (Diário de campo, 8 de janeiro de 2016).

De fato, ao longo de todo o trabalho de campo, sempre ouvi histórias sobre militantes que haviam se retirado de cena por terem tido acesso facilitado a políticas de moradia, como retribuição por apoio dado a eleições e reeleições de determinados candidatos à presidência da FASC. Pelo mesmo motivo, esses "beneficiados" teriam se afastado da mobilização social, seguindo suas próprias vidas, ou expulsos do MNPRRS. São histórias difusas, geralmente sem rostos, sem nomes e sem datas, mas que, de certa forma, incidem sobre a atenção e a reflexão que os atuais militantes privilegiam quando o assunto é a relação com agentes, órgãos e instituições de Estado e de governo. São essas mesmas narrativas pretéritas, contadas em tom de reprovação, que parecem incitar os sujeitos a se autoafirmarem como "espiões" que adentram a sede da fazenda de domesticação apenas para espreitar e questionar sua administração.

Narrativas similares foram identificadas na pesquisa de Pedro Leite (2016), 
também entre os militantes do MNPR-RS. Sem se deter com profundidade nesta questão, Leite refere a polêmica que se cria em torno de sujeitos que investem na autopromoção e que atuam em espaços institucionais para tirar "proveitos individuais", sugerindo que atuações desse tipo promovem o afastamento e a destituição de legitimidade para falar em nome dos coletivos de mobilização. Mencionando casos semelhantes para o mesmo contexto de pesquisa, Schuch (2015) mostra que os militantes que buscam se autorrepresentar ou encontram caminhos alternativos à rua, também são lembrados negativamente e, em algumas situações, são expulsos da mobilização ou fazem com que o próprio grupo se desarticule.

Os motivos apresentados para tais acontecimentos, mencionados por Leite (2016) e Schuch (2015), são similares aos que justificaram o único caso de expulsão que pude acompanhar de perto, deflagrado por tentativas de concentrar poder, autoridade e representação nas mãos de uma única pessoa. Foi o que aconteceu com Ricardo, em setembro de 2014. Esse homem de aproximadamente 40 anos sempre esteve envolvido em diferentes coletivos de mobilização e visibilização da população em situação de rua na cidade. Uma conversa informal com o pesquisador e colega Bruno Fernandes ${ }^{9}$, que acompanhou de perto a circulação de Ricardo entre diferentes organizações, sobretudo no Boca de Rua ${ }^{10}$, me esclareceu que a sua inserção no Programa Fome Zero exigia uma série de mediações com serviços disponibilizados pelos gabinetes de alguns vereadores, como impressão de documentos e uso de telefones, além de parcerias com algumas secretarias municipais, no objetivo de angariar apoio e recursos para ações voltadas a pessoas em situação de "vulnerabilidade social".

A sua saída do MNPR-RS ocorreu em uma única reunião, quando, nos meses subsequentes à Copa do Mundo, os militantes discutiam com o secretário municipal de direitos humanos a reabertura do Restaurante Popular na cidade. Em uma dessas reuniões, os militantes e apoiadores anunciaram a decisão consensual de que Ricardo não representava mais o movimento, uma vez que vinha firmando vínculos com a FASC, e concedendo entrevistas na mídia, explicitando aquelas parcerias e falando em nome do movimento, sem o consentimento de seus integrantes.

O ponto central a destacar como razão pela qual a participação de Ricardo vinha sendo desqualificada no MNPR-RS é a extrema proximidade com determinados partidos políticos e com alguns órgãos da administração municipal. Ou seja, o seu desligamento ocorreu não apenas por ter exercido uma política de autorrepresentação, mas sobretudo pela publicidade concedida a vínculos institucionais indeseja- 
dos, que faziam dele uma pessoa não digna de confiança e que, ao mesmo tempo, apresentava-se como um "sujeito que deu certo" e que correspondeu às expectativas mais comuns da fazenda de domesticação: a "recuperação". A postura de Ricardo, no entanto, foi muito simples: aceitou o desligamento e continuou a atuar no Fórum Rua, não deixando de manifestar o quanto, na sua opinião, a mobilização social deixaria de ganhar visibilidade ao evitar certas parcerias.

A meu ver, o que ocorreu com Ricardo expressa uma relação complexa entre os esforços coletivos para "tirar as pessoas das ruas" e a lógica individualizante e neoliberal que perpassa e conduz as ações e os discursos estatais, sobretudo no campo da assistência social - quando o Eu se sobrepõe ao Nós. De fato, "superar a situação de rua", desenvolver "processos de saída das ruas" e promover o seu "enfrentamento", construir "autonomia" e "independência” por meio do acesso à renda, à educação e à moradia; ingressar no mercado de trabalho por meio de programas de qualificação profissional e incentivar a "convivência familiar” (BRASIL, 2013, 2009) são objetivos apresentados por órgãos governamentais nacionais, como o MDS, e organizações internacionais, como a UNESCO, como indispensáveis para a “erradicação da pobreza” e para o "desenvolvimento social”. Em parte, Ricardo dava carne e sangue a esses ideais e, embora não estivesse trilhando um caminho distante dos que passam por experiências semelhantes, era extremamente significativo o fato de apresentar-se, em algumas ocasiões, como um “vencedor", estando à frente de projetos voltados à doação de alimentos, à confecção de documentos de identidade e a oficinas de trabalho e renda - sempre aberto às mediações e diálogos com entidades e instituições estatais, como a FASC.

Tal atuação implicava um posicionamento específico em relação aos órgãos estatais. Ricardo não poderia ser acusado de ter "virado as costas" ou "abandonado seus companheiros", mas a posição que ocupava nesse campo nebuloso de intervenção sobre a questão da "situação de rua" era problemática porque lhe concedia certa distinção e prestígio, fazendo com que se destacasse em relação aos demais.

Estou ciente dos perigos nessa evidente redução da experiência de Ricardo ao campo institucional. Não tive acesso, e talvez poucos militantes do MNPR tenham tido, à complexidade de tal inserção e do quanto essas mediações poderiam significar um território estratégico de militância política, no qual, talvez, ele atuasse sabendo muito bem de sua toxicidade, desvencilhando-se dela na dimensão prática e cotidiana de suas ações. O que me é possível inferir, no entanto, é que o desligamento de Ricardo sinaliza a reprovação não de suas decisões e opções individuais, 
mas de um processo de formação de indivíduos que se destacam em relação ao coletivo. Repelir esse processo era uma forma de evitar estreitos canais de comunicação e, consequentemente, de dependência, subordinação e controle.

Ainda é possível sugerir que, quando se critica a postura de Ricardo, também se afasta qualquer referência ou vinculação que se possa fazer entre os integrantes do MNPR-RS e certas instituições. Vivenciei diferentes situações marcadas por relatos sobre sujeitos supostamente "cooptados" pela FASC. Ironicamente, eram esses casos - vistos por muitos como resultado positivo das políticas públicas - que se tornavam alvo de recusa. Com esses mecanismos de controle e rejeição do indesejado, os militantes e apoiadores do MNPR mantinham a afronta à autoridade e legitimidade estatal e reduziam as possibilidades de total domínio sobre a mobilização social.

\section{Forças que se cruzam, mas não se fundem}

A mesma lógica que parecia operar sobre o desligamento de Ricardo replicava-se na insistente preocupação com o uso dos símbolos do MNPR-RS, como a bandeira e a camiseta do movimento. Circulando pelo país nas cores azul ou vermelha, tendo ao centro os contornos territoriais do mapa do Brasil, esses símbolos são, igualmente, objetos que devem ser protegidos de qualquer contaminação que não seja estratégica. Não foram raras as experiências de campo nas quais pude visualizar um exímio cuidado para que os símbolos do MNPR estivessem no "lugar certo" e sendo utilizados pelas "pessoas certas", garantindo que, quando seus usos fugissem a essa "regra", tudo não passasse de uma estratégia política.

Uma dessas experiências ocorreu durante a cerimônia de reabertura do Restaurante Popular em Porto Alegre, realizada no dia 25 de fevereiro de $2016^{11}$. Às $11 \mathrm{~h}$ da manhã, em um prédio localizado no Bairro Floresta, distante a meia hora a pé do centro da cidade, aglomeravam-se pessoas muito bem vestidas para a solenidade, a maioria vinculada aos governos municipais e estaduais, funcionários da rede socioassistencial, além de policiais militares, seguranças, fotógrafos e repórteres de rádio e TV que, por repetidas vezes, entrevistavam o Secretário Municipal de Direitos Humanos. Nesse cenário de múltiplas interações, muitas outras pessoas começavam a formar uma fila para almoçar no primeiro dia do novo restaurante popular.

Aparentando ter não mais do que 40 anos, dois homens aproximaram-se da porta central do restaurante e ali ficaram, entre os assessores de imprensa e de governo estadual e municipal. Um deles vestia a camiseta vermelha do MNPR. Por carregar esse símbolo no corpo, logo atraiu a maioria dos repórteres que cobriam 
o evento e que passaram a entrevistar o até então desconhecido “militante". Entre as perguntas que eram realizadas pelos profissionais de imprensa, identifiquei uma linha especulativa comum: a transformação que a reabertura do restaurante popular provocaria na vida das pessoas “em situação de rua”. Com uma voz mansa e quase inaudível, aquele homem, cercado de gravadores, câmeras e microfones, humildemente explicou que, a partir daquele dia, ele teria um lugar onde poderia se alimentar, sem gastar muito e sem precisar "pedir comida nas ruas". Ao mesmo tempo, era possível ouvir o Secretário de Direitos Humanos afirmar, para outros repórteres, que a abertura do restaurante representava um importante passo rumo à construção da dignidade das camadas mais pobres da população, simbolizando a luta contra uma sociedade injusta e desigual.

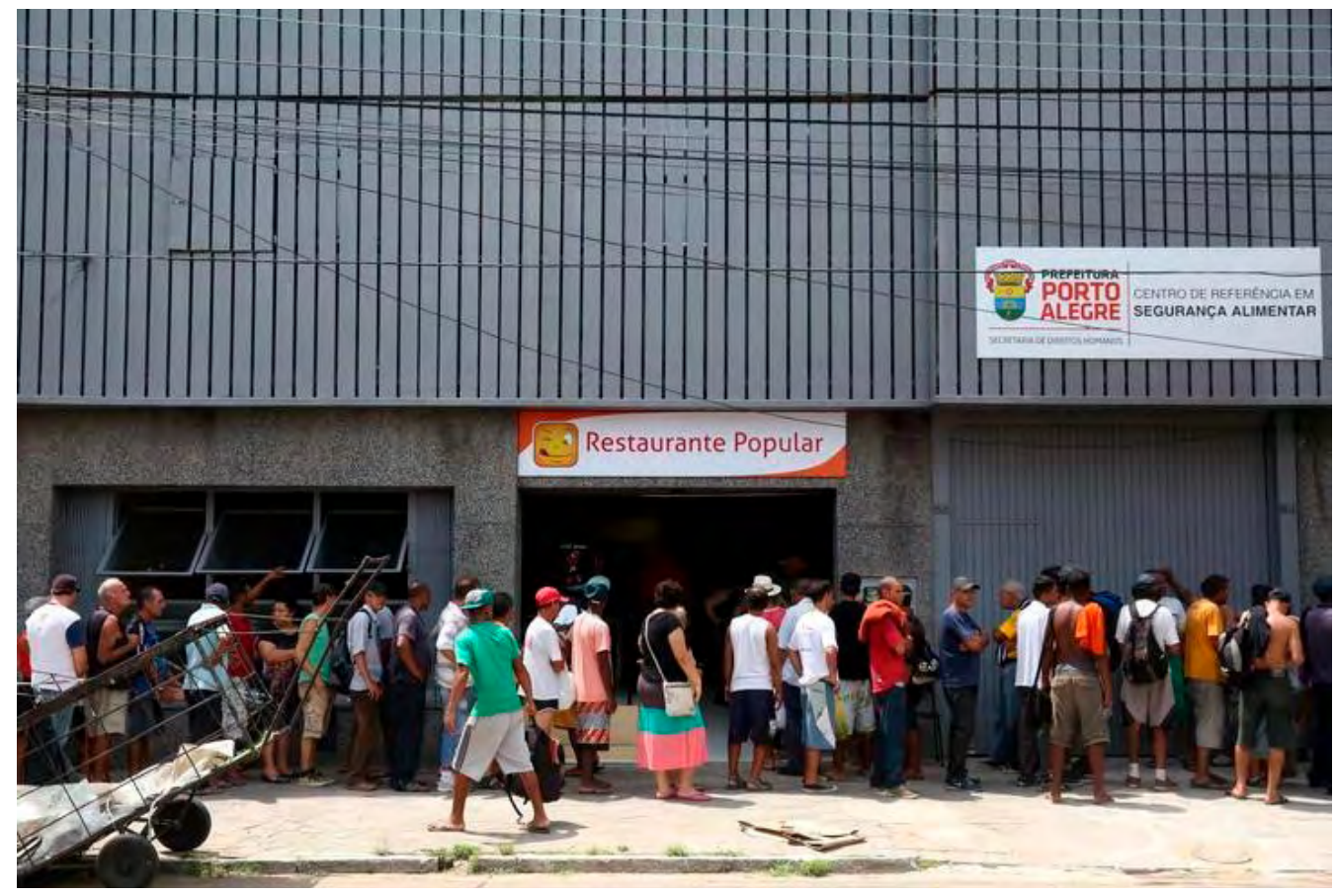

Imagem 1: Entrada do restaurante popular.

Fonte: Jornal do Comércio, Porto Alegre, 2016

Outros militantes do MNPR-RS chegaram ao prédio assim que aquela entrevista foi concedida. Um deles, quando soube que havia alguém usando indevidamente os símbolos do movimento, quis de imediato saber quem ele era e onde estava. Mas fomos surpreendidos pela chegada do então prefeito José Fortunati (PDT) e do 
governador José Sartori (PMDB), que adentraram o prédio levando consigo a multidão de profissionais que os aguardava. Quando consegui atravessar uma densa aglomeração de pessoas, encontrei militantes e apoiadores do MNPR-RS conversando com o homem que vestia a camiseta do movimento, questionando a origem daquela aquisição e alertando sobre o fato de que ele não deveria estar falando em nome da população em situação de rua. Respondendo vagamente algumas questões, aquele interlocutor demonstrou estar assustado com a situação, parecendo realmente não saber muito bem o que estava acontecendo. Outros apoiadores intervieram para acalmar os ânimos, sugerindo que o grupo convidasse aquele sujeito para participar das reuniões semanais do movimento, passando, de fato, a integrar o MNPR.

Eram posicionamentos distintos que estavam em jogo: vestindo a camiseta do MNPR e legitimando "a visão governamental” sobre o papel inquestionável de suas ações rumo à superação da "pobreza e desigualdade", aquele sujeito fazia com que, na visão de militantes e apoiadores, o movimento fosse alvo de uma estratégia política que colocava seus integrantes publicamente ao lado das autoridades governamentais, numa posição indesejada, na medida em que ocultava o peso de suas mobilizações na reinauguração do restaurante. Tanto é que, nas falas públicas que compuseram o ritual de inauguração, os militantes do MNPR não tiveram nenhum espaço para se colocar.

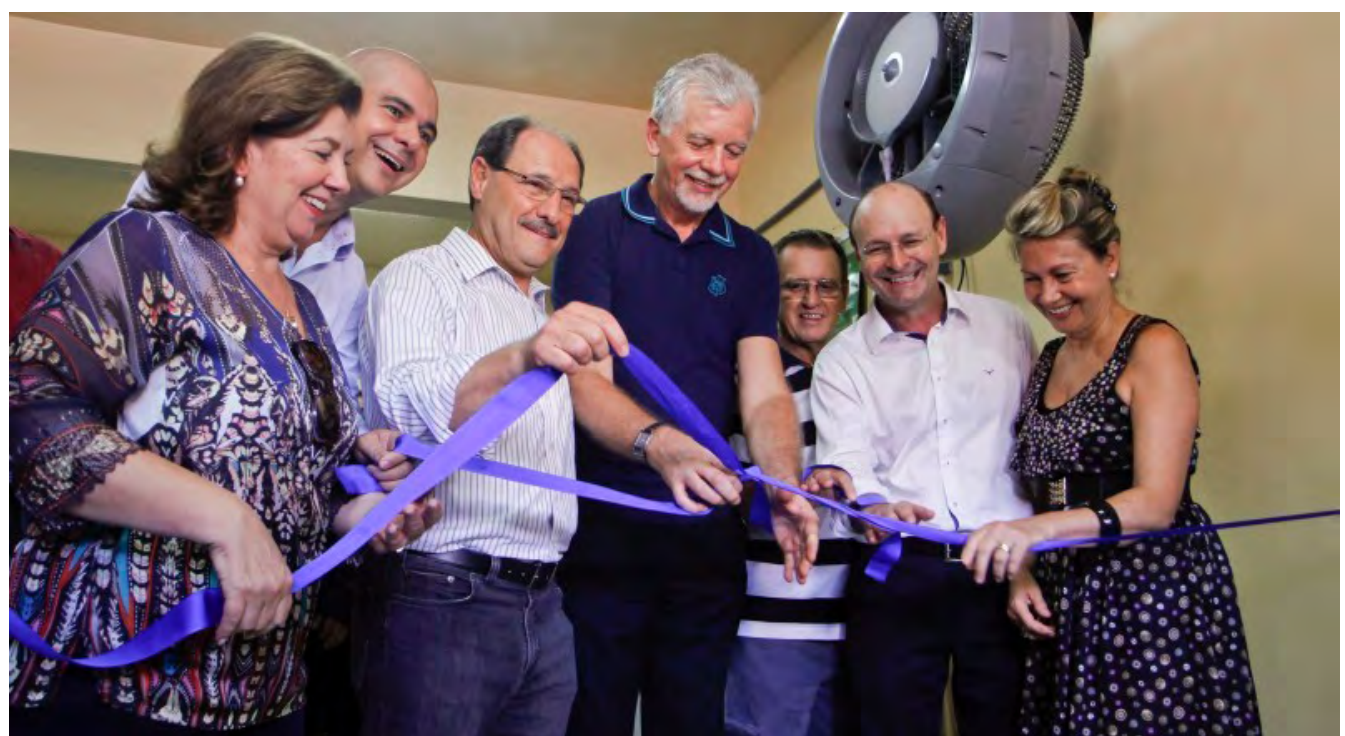

Imagem 2: cerimônia de abertura do Restaurante Popular.

Fonte: Jornal do Comércio, Porto Alegre, 2016 
A cerimônia de reinauguração contou com a presença de autoridades governamentais que celebraram e positivaram aquela ação como um avanço rumo à "construção da cidadania”. No entanto, o bônus deste "avanço" foi discursivamente depositado na conta dos representantes políticos presentes, que não referenciaram a mobilização realizada pelo MNPR para que aquele dia tão esperado chegasse, após anos de desinteresse do poder público.

Os militantes e apoiadores já esperavam tal desenrolar dos fatos, pois a prefeitura não enviou nenhuma notificação ou convite formal ao movimento. Por isso, muitos decidiram marcar presença na cerimônia e, também por isso, tiveram certeza de que aquele homem desconhecido, estampando no peito os símbolos de uma luta nacional pelos direitos da população de rua, era um "convidado especial”, estando ali no objetivo único de substituir o posicionamento crítico dos integrantes do MNPR-RS e legitimar a "visão governamental". Dois meses depois, em entrevista ao Canal Paralelo ${ }^{12}$, alguns militantes expuseram seus contrapontos, trazendo a mobilização promovida pelo movimento para o centro da discussão. Vestindo a camiseta vermelha do MNPR, Marcos declarou:

Nós ajudamos a construir tudo, e no fim, quem está tomando consciência e peso de tudo é a prefeitura, é o atual governo que também está fazendo propaganda para eleger os próximos. [...]. Nós fizemos tantas reuniões, umas três, quatro audiências públicas. Imagina tu chegares e não te convidarem para nada! É como eu ajudar tu fazer a festa de aniversário e depois não ser convidado. Está faltando é o governo reconhecer o nosso trabalho, porque nós não ganhamos nada, eu não ganho nada para fazer isso. O que eu ganho é a minha moral (Canal Paralelo, 17 de abril de 2016).

Foi preciso fazer uma espécie de correção discursiva em forma de revide. O que não se poderia admitir era a cristalização hierárquica de uma posição subalterna sobre um contingente populacional que recebe passivamente as "benesses do Estado", sem contestar ou reivindicar reconhecimento de sua inserção ativa, propositiva e combativa na formulação das políticas públicas. Inverter este quadro, fortalecido pela voz titubeante de um sujeito "cooptado pelo governo", tornou-se fundamental para que os elementos de composição, de harmonia, de concordância e de subalternidade fossem desfeitos ou, ao menos, abalados. Por isso, foi indispensável estampar a camiseta do MNPR no peito, marcar a dimensão da luta e do enfrentamento sem o qual a reabertura do restaurante popular não teria ocorrido, afirmar 
que toda aquela performatividade estatal (Blázquez, 2012) guardava interesses políticos e, ainda, sugerir que o protagonismo dos militantes e apoiadores foi ocultado e desprezado pelas autoridades públicas. Na voz de Marcos e de outros integrantes do MNPR-RS, nenhuma palavra foi dita a respeito de "transformações" que aquele equipamento público provocaria na vida das pessoas. Todos sabiam muito bem que era exatamente isso que "eles" queriam ouvir.

O que tudo isso parece nos dizer é que, assim como seus integrantes, os símbolos da máquina de guerra também não devem chegar tão perto do aparelho de captura a ponto de declarar publicamente seus vínculos insuperáveis - ainda que indesejáveis. Podem estar juntos, nos mesmos espaços, nos mesmos discursos, nos mesmos eventos, mas suas diferenciações, assim como o caráter agonístico de suas relações devem ser ressaltados, relembrados, estampados o tempo todo. O que vale destacar é que esses diferentes sujeitos procuram manter uma distância mínima em reação ao Estado, que possibilite o diálogo sem sobreposições e sem fusões: são linhas que se cruzam, mas não se fundem e jamais se fecham em círculos concêntricos e ideais, dispostos igualmente em um território compósito e unificado no qual todos falam a mesma língua e estão o tempo todo do mesmo lado (Deleuze \& Guattari, 1997).

\section{Últimas reflexões: a resistência de uma luta nômade}

O que, a meu ver, se impõe do início ao fim nas experiências etnográficas aqui descritas, são esforços individuais e coletivos contra a cristalização de autoridades e hierarquias que permitam o avanço dos latifúndios da fazenda de domesticação. Falar por si sem a construção coletiva e estratégica do que e para quem falar é falta gravíssima, pois corre-se o risco de falar o que "eles", os que não estão “do nosso lado", querem ouvir. Por isso, entende-se que o sujeito que se destaca corre o risco de não só negligenciar a discussão coletiva, mas principalmente, de aderir, como refém (e não como espião), aos discursos que legitimam as instituições estatais.

O que se torna extremamente curioso e interessante é a semelhança entre a regulação exercida sobre certos militantes que se deixam "atrair" pelas promessas estatais e a dinâmica de circulação de bens entre pessoas em situação de rua no município de Pelotas, explorada em minha dissertação de mestrado (Lemões, 2013). O que, à época, me impressionava era a inexistência de conflitos graves entre os companheiros em situação de rua que, mesmo sabendo quem havia furtado seus bens, jamais identificavam os alvos de suas desconfianças, tampouco se insurgiam contra eles. Sabendo que a ostentação de um relógio ou de um celular feria alguns 
dos valores cruciais naquele contexto - a partilha e a coletividade -, o sujeito lesado tinha ciência de que o objeto que antes o distinguia, mas que desapareceu, retornaria para o grupo em que estava inserido, sob a forma de alimento ou outros itens a serem compartilhados entre todos. Tais considerações me levaram a concluir que...

[...] possuir determinados bens soa como uma traição. É como se o detentor estivesse simbolicamente passando para o "outro lado": o lado dos "desiguais", daqueles que ostentam em demasia, que acumulam cada vez mais e exibem-se aos olhos dos que nada possuem. Nesse sentido, o roubo teria o papel de regular a igualdade material entre os pares de rua, sem, contudo, acarretar conflitos com o poder de romper as relações (Lemões, 2013:208-209).

O desprezo pela acumulação de bens nas mãos de uma única pessoa é combatido porque eleva uns sobre os outros, apresentando sinais de poder e hierarquia que, mesmo passageiros e simbólicos, destacam indivíduos, ferem a reciprocidade entre os iguais e aproximam aquele que acumula ao universo dos que, em posição "superior", ostentam frente aos que "nada possuem". Contrapor-se ao acúmulo de bens e, no caso do MNPR, ao acúmulo de poder, prestígio e destaque, parece caminhar para o mesmo intento: evitar o cruzamento com linhas que tudo enraízam, ao invés de fazer com que as coisas circulem, sejam elas objetos de valor ou poder de fala e visibilidade. Bens demais, poder demais, perigo demais.

Há muitos anos, Clastres (2011 [1974]) nos mostrou que certos grupos não cessam de investir contra aquilo que é destinado a destruí-los: a centralização do poder e, sobretudo, o respeito ao poder, o desejo de poder. Por isso, o esforço permanente das sociedades indígenas sul-americanas em separar poder e prestígio, de modo que nada - nem mesmo a glória das vitórias da guerra - permita o comando de um sobre outros, se traduz num trabalho coletivo que impede a insistente formação estatal: "é o esforço permanente para impedir o chefe de ser chefe, é a recusa da unificação, é o trabalho de conjuração do Uno, do Estado” (Clastres, 2011:186) ${ }^{13}$.

Entre os Guayaki paraguaios, Clastres revela que o guerreiro só acessa o prestígio (sempre passageiro) de suas vitórias, quando o seu desejo de guerra coincide com o desejo coletivo de guerrear, caso contrário, o chefe guerreiro pode utilizar a sociedade para atingir objetivos individuais, transmutando prestígio em poder. A morte física (ou social) é, com frequência, o destino de guerreiros que assim procedem, uma vez que "isolar o poder político é impossível na sociedade primitiva, não há lugar, não há vazio que possa ser preenchido pelo Estado” (Clastres, 2011:179) ${ }^{14}$. 
Como já apontou Schuch (2015), as mobilizações que precederam a fundação do MNPR em Porto Alegre apresentavam dinâmica semelhante à demonstrada por Clastres, uma vez que tais formas de mobilização se traduzem num "movimento que se movimenta”, ou seja, que se desagrega toda vez que líderes se destacam de diferentes formas.

Essa mesma dinâmica é, também, esparramada pela rede de relações tecidas no "universo das ruas", mostrando que o líder, aquele que se torna referência em cada agrupamento, não tem poder de mando e autoridade. Ele pode aconselhar, propor regras, mas jamais deseja a posição de domínio sobre o grupo. Tomamos o exemplo de Marcos, "militante em situação de rua", que deixou tal questão explícita quando nos encontramos em um sábado de novembro de 2015, em uma feira ecológica do centro da capital gaúcha, ocasião em que ele vendia jornais do Boca de Rua. Enquanto conversávamos em meio ao vaivém de pessoas, um casal aproximou-se de nós e entregou dois pacotes de produtos integrais a Marcos, que agradeceu e perguntou se, no próximo domingo, eles iriam em sua "aldeia" (termo utilizado para designar grupamentos urbanos de rua). O homem, de aproximadamente 50 anos, respondeu que teria outro compromisso e, em seguida, orientou Marcos a cuidar melhor da sua horta. Foi então que consegui entender minimamente do que se tratava o diálogo: o casal era vinculado a algum movimento de agroecologia, e há algum tempo vinha estimulando Marcos e seus companheiros a cultivar uma horta no terreno onde estavam alojados. Em tom de repreensão, ele continuou:

Tem que limpar na volta, tirar a palha e usar o carrinho para aguar. Tu tens que liderar, Marcos! Tem que ter um líder para fazer as coisas acontecerem. A limpeza vocês fazem só três vezes por semana, mas tem que fazer mesmo! Imagina se depois dá certo e tu começa a espalhar essa ideia para as outras aldeias, os caras vão fazendo também. Quem sabe depois tu vais lá para o nosso encontro nacional e consegue espalhar isso nacionalmente. E tu vais ser o cara que vai começar isso, mas tem que ter liderança (Diário de campo, 14 de novembro de 2015).

Marcos ouvia com atenção e, vez ou outra, sinalizava concordância. Assim que os conselhos foram dados, o casal despediu-se de nós. Quando nos vimos sozinhos novamente, Marcos comentou comigo: "ele só pode estar louco! Como vou liderar as pessoas lá na aldeia? Quem sou eu para mandar nos outros? Eu já fui morar na rua para não ser mandado, como é que eu vou mandar agora?".

Ao descrever essas interações, argumento a respeito da possível transposição de 
uma dinâmica de organização coletiva das ruas para a mobilização social por direitos. Essa transposição insurge-se contra a figura da autoridade, da hierarquia e do prestígio individual que, a todo tempo e por diferentes vias, insiste em criar raízes no seio de um coletivo inclinado a funcionar como máquina de guerra, desterritorializando tendências arborescentes, rígidas, centralizadas e produtoras de sujeitos ideais à lógica neoliberal, centrada na figura do indivíduo autônomo, recuperado e empoderado. Nos termos de José Carlos dos Anjos (2006), o que essa disposição nômade desafia é a forma como a cultura ocidental representa o poder: sempre unívoco, baseado no exercício espetacular do poder estatal, obcecado por uma comunicação rostificada, representada em corpos individuais e individualizados. Isso explica, em parte, a obsessão estatal na busca de um líder, de uma concentração de força personificada e que organize a ressonância dos centros de poder com a mesma natureza concêntrica estruturada pelo Estado (Barbosa, 2001; Biondi, 2009; Marques, 2010).

Nada disso, no entanto, insinua que as pessoas “em situação de rua”, militantes do MNPR ou não, estejam deixando de lado as "oportunidades” de lutar efetivamente pela conquista e garantia de seus direitos, ao erigirem mecanismos para barrar os aspectos que consideram nocivos dessa proclamada parceria construtiva com as instituições estatais. Ninguém melhor do que eles sabe que se deve confiar desconfiando, pois são sujeitos que narram com a voz, com o corpo, com a memória, as marcas da violência estatal, perpetrada por agentes das instituições de segurança pública, assistência social, habitação, saúde e tantas outras.

$\mathrm{O}$ que se quer reforçar é que frente às atuações e concepções nativas sobre Estado e políticas públicas neoliberais, nos deparamos com a potencialidade dos conceitos filosóficos aqui explorados para fazer eclodir outra perspectiva teórico-reflexiva sobre pessoas em situação de rua no Brasil. O que o viés aberto pela leitura na chave da máquina de guerra nos possibilita apreender são pessoas de carne e osso respondendo às décadas de visibilidade violenta, perpetrada por um Estado que sempre esteve de olhos bem abertos em relação às suas populações indesejáveis ao "projeto civilizacional" - visibilizando-as negativamente desde o seu braço penal e punitivo (Lemões, 2018).

Por isso, ao invés de reiterar uma percepção já consolidada em certa bibliografia sobre o tema no Brasil - calcada em posições explicativas que retomam as contradições do sistema capitalista, as mudanças estruturais na economia, as sucessivas crises mundiais, o acirramento das desigualdades socioeconômicas e a ausência de 
políticas públicas (ROSA, 2005; BURSZTYN, 2000; NEVES, 2010, entre outros) -, a lente privilegiada neste artigo redirecionou o foco para a constatação de que movimentar-se como máquina de guerra é conduzir uma luta nômade pelos direitos, que invade latifúndios da fazenda de domesticação, exige participação nas colheitas, mas não deixa de denunciar o veneno, a toxidade encharcada no solo pelos "grandes produtores”. É o que, minimamente, possibilita a produção de fissuras em imagens humanitárias que o Estado constrói sobre si tão logo surge a oportunidade de atuar conjuntamente com grupos e populações marcadas pela violência de seu braço repressivo. Por essas fissuras, também se criam possibilidades para reduzir as coordenadas institucionais que, por todos os lados, buscam nortear os passos de uma luta nômade. Oscilando entre a denúncia e a reivindicação, essas pessoas declaram guerra aos favorecimentos e negociação de "migalhas" oferecidas em troca de lealdades, e exigem respeito, dignidade e visibilidade, nem que para isso precisem atuar como espiões e vestir-se com as armaduras de um guerreiro nômade.

Recebido: $30 / 07 / 2018$

Aprovado: 10/04/2019

Tiago Lemões é pós-doutorando em Antropologia (PPGAnt/UFPel). Doutor em Antropologia Social (PPGAS/UFRGS), com doutorado-sanduíche na Université Paris VIII. Possui experiência nas áreas de Teoria pós-colonial e Antropologia do Estado, dialogando com os seguintes temas: população em situação de rua, racismo, políticas públicas, direitos humanos, poder e governamentalidade. Orcid: 00000002-3538-3414.Contato: tiagolemoes@gmail.com

\section{Notas}

1. Em março de 2012, o Superior Tribunal de Justiça negou o pedido do Ministério Público de levar a julgamento quatro policiais envolvidos diretamente nas mortes. Para uma análise detalhada sobre o andamento do inquérito policial que apurou os referidos crimes, ver Mata (2006).

2. Este artigo configura o resultado de uma revisão, ampliação e aprofundamento analítico do sexto capítulo de minha tese de doutorado, defendida em 2017 (PPGAS/UFRGS), sob orientação de Patrice Schuch e com financiamento da CAPES. Recentemente, as reflexões aqui desenvolvidas 
foram apresentadas no painel Anthropology of contemporary states: institutions of public administration, population management and symbolic production of state centrality, coordenado por Antonio Carlos de Souza Lima e Laura Navallo Coimbra, por ocasião do 18th IUAES World Congress. Agradeço enormemente aos coordenadores do referido painel pelas valiosas e potentes contribuições ao trabalho apresentado.

3. O termo "conjurar" assume aqui o sentido de tramar, conspirar, afugentar algo que não se quer por perto em demasia. Sua utilização semântica, neste texto, inspira-se no movimento descrito por Pierre Clastres (2011) para caracterizar os meios utilizados por organizações sociais indígenas para impedir a formação de conjuntos sócio-políticos integrados e centralizados, o que configura, para o autor, um modo eficaz de impedir a emergência unificadora do Estado, sobretudo entre os Guayaki paraguaios, com os quais realizou pesquisa etnográfica.

4. Atualmente, porém, o MNPR vem constituindo, a nível nacional e regional, o que os militantes denominam de Frente Feminina e Frente LGBTT: coletivos que compõem segmentos da mobilização social que buscam ampliar a diversidade de militantes e, ao mesmo tempo, explicitar a desigualdade nos espaços de representatividade no movimento social. Em Porto Alegre, esse processo tem ocorrido a partir da interiorização do movimento e da articulação de militantes em situação de rua ativos no debate de gênero e sexualidade em municípios do interior do estado.

5. Agradeço a oportunidade de repensar e considerar os atravessamentos de gênero que incidem sobre nossas análises, aprendizado que só foi possível em virtude das críticas e sugestões realizadas pelxs pareceristas anônimxs da Anuário Antropológico, que também apontaram uma série de outras questões extremamente relevantes para a qualificação deste texto.

6. A cidade de Porto Alegre foi palco de diferentes grupos de mobilização pelos direitos da população em situação de rua, organizados por usuários de serviços assistenciais, trabalhadores da rede pública de assistência social e ONG's locais, que tiveram visibilidade entre as décadas de 1990 e 2000, antes de se vincularem ao movimento nacionalizado, em 2013. Um histórico pormenorizado da atuação dessas mobilizações pretéritas consta no segundo capítulo de minha tese de doutorado (Lemões, 2017).

7. Optei por criar um nome fictício para o município e para os interlocutores, a fim de não identificar o local e nem os atores envolvidos na experiência relatada a seguir, no objetivo de minimizar prejuízos que porventura possam recair sobre os envolvidos nas cenas descritas.

8. Centro de Referência Especializado para a População de Rua (Centro-Pop) - um serviço instituído em 2009 pelo governo federal e discursivamente voltado ao desenvolvimento de relações de solidariedade, respeito e convívio social de mulheres e homens que vivem nas ruas.

9. Bruno Fernandes é graduando em Ciências Sociais (UFRGS) e tem se engajado política e academicamente com os coletivos dedicados à luta pelos direitos das pessoas em situação de rua em Porto Alegre. Sou grato a esse colega e amigo pela partilha de reflexões e experiências de campo ao longo de três anos de pesquisa - agradecimento que se estende a Gabriela Jacobsen e Pedro Leite, que também atuaram como pesquisadores e apoiadores do MNPR.

10. O jornal Boca de Rua, do qual a maioria dos atuais militantes do MNPR-RS faz parte, é fruto de um descontentamento com as tendências conservadoras da imprensa gaúcha. Criado em 2000 por duas jornalistas, assumiu o papel de dar ressonância às "vozes de uma gente invisível”, conjugando denúncias de múltiplas violências, preconceitos e violações. Para uma análise do papel político do 
Boca de Rua, ver Jaenisch, 2007.

11. Tendo funcionado de 2005 a 2013, nos arredores da Rodoviária, o restaurante popular foi interditado por falta de Plano de Prevenção Contra Incêndios. Três anos depois, após uma série de negociações entre os anos de 2014 e 2015, envolvendo integrantes do MNPR, da FASC, da Secretaria de Direitos Humanos e da Comissão de Defesa do Consumidor e Direitos Humanos da Câmara de Vereadores de Porto Alegre, o restaurante foi finalmente reinaugurado, passando a servir 600 refeições diárias.

12. A entrevista está disponível na íntegra no site do Canal: https://www.youtube.com/watch?v= DvVsuf2oCdI

13. Do original: “c'est l'effort permanent pour empecher les chefs d'être chefs, c'est le refus de l'unification, c'est le travail de conjuration de l'Un, de l'Etat” (Clastres, 2011:186). Tradução do autor.

14. Do original: "le pouvoir politique séparé est impossible dans la société primitive, il n'ya pas de place, pas de vide que pourrait combler l'Etat" (Clastres, 2011:179). Tradução do autor.

\section{Referências bibliográficas}

ANJOS, José Carlos dos. 2006. No território da linha cruzada: a cosmopolítica afro-brasileira. Porto Alegre: Editora da UFRGS.

BRASIL. Política Nacional para a População em situação de rua. Decreto n. 7.053, 2009. Disponível em: http://www.planalto.gov.br/ccivil_03/_Ato2007-2010/2009/Decreto/ D7053.htm. Acesso em: 10 abr. 2019.

BRASIL. Diálogos sobre a população de rua no Brasil e na Europa: experiências do Distrito Federal, Paris e Londres. Brasília: SDH, 2013.

BARBOSA, Antônio Rafael. 2001. "Segmentaridade e tráfico de drogas no Rio de Janeiro”. Alceu, v. 2, n. 3 .

BIONDI, Karina. 2010. Junto e misturado: uma etnografia do PCC. São Paulo: Terceiro Nome.

BLÁZQUEZ, Gustavo. 2012. "Fazer cultura. Fazer-se Estado. Vernissages e performatividade de Estado em Córdoba”. Mana, Rio de Janeiro, v. 18, n. 1, pp. 37-61.

BURSZTYN, Marcel (org.). 2000. No meio da rua. Nômades, Excluídos eViradores. Rio de Janeiro: Garamond.

CLASTRES, Pierre. 2011. La société contre l'État. Paris: Les Éditions de Minuit.

DE LUCCA, Daniel. 2008. "Vidas de Rua em Jogo: políticas públicas, segurança e gestão da população de rua em São Paulo”. In: Seminário Nacional População em situação de rua, 2008, São Carlos. Anais do Seminário.

DELEUZE, Gilles; GUATTARI, Félix. 1996. Mil Platôs. Capitalismo e Esquizofrenia., v. 3. Rio de Janeiro: Editora 34.

DELEUZE, Gilles; GUATTARI, Félix. 1997 Mil Platôs. Capitalismo e Esquizofrenia, v. 5. Rio de Janeiro: Editora 34.

FERNANDES, Talita. 2019. Rua, substantivo feminino: mulheres em movimento e o direito ao corpo na 
cidade. Dissertação de mestrado [Programa de Pós-Graduação em Geografia]. Porto Alegre: Universidade Federal do Rio Grande do Sul.

JAENISCH, Samuel. 2007. "Vozes de uma gente invisível: o jornal Boca de Rua como espaço de mediação”. In: Soraya Fleischer, Patrice Schuch, Cláudia Fonseca (orgs.). Antropólogos em Ação: experimentos de pesquisas em Direitos Humanos. Porto Alegre: Editora da UFRGS, p. 121-131.

LEITE, Pedro. 2016. Na luta com os peregrinos. Uma etnografia experimental com a população em situação de rua de Porto Alegre. Monografia [Graduação em Ciências Sociais]. Porto Alegre: Universidade Federal do Rio Grande do Sul.

LEIRNER, Piero. 2012. "O Estado como fazenda de domesticação”. Revista de Antropologia da UFSCar, v. 4, n. 2, p. 38-70.

LEMÕES, Tiago. 2013. A família, a rua e os afetos: uma etnografia da construção de vínculos entre homens e mulheres em situação de rua. São Paulo: Novas Edições Acadêmicas.

LEMÕES, Tiago. 2017. De vidas infames à máquina de guerra: etnografia de uma luta por direitos. Tese [Doutorado em Antropologia Social]. Porto Alegre: Universidade Federal do Rio Grande do Sul.

LEMÕES, Tiago. 2018. O Estado de olhos bem abertos. Um debate sócio-histórico sobre violência, massacre e direitos da população de rua no sul do Brasil. In: Márcia de Calazans, Mary Garcia, Emília Piñeiro (orgs). América Latina. Corpos, trânsitos e resistências. Porto Alegre: Editora Fi.

MARQUES, Adalton. 2010. "Liderança”, "proceder" e "igualdade”: uma etnografia das relações políticas no Primeiro Comando da Capital. Etnográfica, v. 14, n. 2.

MATA, Paulo. 2006. O massacre da Praça da Sé. Monografia [Graduação em Jornalismo]. Campinas: Pontífica Universidade Católica de Campinas.

NEVES, Delma. 2010. Habitantes de rua e vicissitudes do trabalho livre. Antropolítica (UFF), v. 2, p. $100-130$.

ROSA, Cleisa. 2005. Vidas de rua. São Paulo: Hucitec.

SARMENTO, Caroline. 2017. O gênero na rua: um estudo antropológico com as mulheres em situação de rua em Porto Alegre. Monografia [Graduação em Ciências Sociais]. Porto Alegre: Universidade Federal do Rio Grande do Sul.

SCOTT, James. 2013. Zomia. Ou l'art de ne pas être gouverné. Paris: Editions Seuil.

SCHUCH, Patrice. 2015. “A legibilidade como gestão e inscrição política de populações: notas etnográficas sobre a política para pessoas em situação de rua no Brasil”. In: Cláudia Fonseca, Helena Machado (org.). Ciência, identificação e tecnologias de governo. Porto Alegre: Editora da UFRGS/ CEGOV. p. 121-145.

WACQUANT, Loïc. 2013. "Marginalité, ethnicité et penalité dans la ville néolibérale: une cartographie analytique”. In: Mathiew Hilgers (org.). État neoliberal et regulation de la pauvreté urbaine selon Lö̈Wacquant. Bruxelles: Université Libre de Bruxelles. p. 17-39. 
A máquina de guerra contra o Estado tóxico: captura e conjuração estatal na luta pelos direitos da população de rua

Resumo: O objetivo deste texto é circunscrever uma teoria nativa do Estado, tendo como substrato um conjunto de mecanismos utilizado por militantes do Movimento Nacional da População de Rua, em Porto Alegre (RS), para conjurar os efeitos perversos da presença estatal na luta por direitos. Para tal, lanço mão de experiências etnográficas para realçar ações cotidianas da militância política que expurgam autoridades, hierarquias e poder de comando entre os sujeitos que mantêm uma proximidade dúbia e perigosa com o Estado. Retomando contribuições de Gilles Deleuze, Félix Guattari e Piero Leirner sobre fenômenos simultâneos de captura e escape, proponho pensar a população de rua como máquina de guerra, cuja principal razão de existência reside na aversão à lógica neoliberal das políticas públicas e na contraposição ao Estado tóxico, do qual se deve manter certa distância para evitar, inclusive, indesejáveis sintomas físicos.

Palavras-chave: população em situação de rua, máquina de guerra, Estado tóxico.
The war machine against the toxic state. Capture and state conjuring in a struggle for rights of homeless people

Abstract: The aim of this text is to highlight a native theory of the State, based on a set of mechanisms used by militants of the Movimento Nacional da População de Rua, in Porto Alegre (RS), to mitigate the perverse effects of the state presence in the struggle for rights. For such purpose, I analyze the ethnographic experiences to highlight the relations between the militants and the agents who are dangerously near to the State. Considering the contributions of Gilles Deleuze, Félix Guattari and Piero Leirner on simultaneous phenomena of capture and escape, I propose to think the action of the homeless people as a war machine whose main reason lies in its aversion to the neoliberal logic of public policies and in the opposition to the toxic State, from which one must keep a safe distance.

Keywords: homeless people, war machine, toxic state. 